\title{
ONLINE EDUCATION: EVALUATION OF STUDENTS PERCEPTION DURING THE COVID-19 PANDEMIC
}

\author{
DANIEL MICAN ${ }^{\mathrm{i}, \text { LUIGIA-GABRIELA STERIE }}{ }^{\mathrm{ii}}$, DAN-ANDREI SITAR-TĂUTiii
}

\begin{abstract}
The pandemic of COVID-19 caused a dramatic shift in education and the educational process. This has had a significant impact on e-learning and m-learning instructional activities via digital platforms, which are now widely used by learners and instructors. The acceptance and use of these platforms is a topic of interest among researchers, and this study seeks to assess users' perceptions of online education during the COVID-19 outbreak. The Unified Theory of Acceptance and Use of Technology (UTAUT) structural model was used to capture behavioral intention and use behavior. The results obtained showed that performance expectancy has the greatest influence on behavioral intention, which has the greatest influence on use behavior. Furthermore, use behavior is largely influenced by behavioral intention, followed by the facilitating conditions, and performance expectancy. In contrast, the results showed that effort expectancy has no effect on behavioral intention. Furthermore, the clear majority of students believe that online education and the usage of e-learning/m-learning technologies are useful, simple to use, and contribute to the more efficient completion of work duties during the learning process. In addition, they aim to continue using online platforms and education in future learning activities.
\end{abstract}

Keywords: online education, m-learning, user perception, technology acceptance, use of technology, behavioral intention, UTAUT

\footnotetext{
i Babeş-Bolyai University, Faculty of Economics and Business Administration Cluj-Napoca, Romania, daniel.mican@econ.ubbcluj.ro

ii Babeş-Bolyai University, Faculty of Economics and Business Administration, Cluj-Napoca, Romania, luigia.sterie@stud.ubbcluj.ro

iii Babeş-Bolyai University, Faculty of Economics and Business Administration, Cluj-Napoca, Romania,dan.sitar@econ.ubbcluj.ro
} 


\section{INTRODUCTION}

\subsection{Why is the Current Essay undertaken?}

Online education has become very popular in recent years, due to the context caused by the COVID-19 pandemic. Under the influence of the COVID-19 pandemic, schools were forced to suspend face-to-face meetings, which affected teaching progress. To minimize the impact of the pandemic on education and control the spread of the pandemic, online teaching has become a necessary strategy during this special period (Chen et al., 2020). Thus, the educational process has moved online, leading to the increase of e-learning and m-learning activities, and teaching has occurred remotely through various digital platforms such as Moodle, Zoom, Google Meet, Microsoft Teams, etc. Online educational platforms allow teachers to provide students with a range of resources and materials in a text or multimedia format. They also allow students to submit assignments online and teachers to keep track of student progress and give grades (Chakraborty et al., 2020). World-renowned faculty have begun to obtain online training certifications to teach their students online, but switching to online has raised many questions about the quality of education (Shahzad et al., 2020).

In the online environment, the methods of learning and teaching are very different from those in the offline environment practiced in the past, and technological advances have led to a number of changes. Thus, in the online environment, the recent educational approach considers that the emphasis should change from teacher to student, making learning and education a personal activity. As a result, it will be more effective when learning conditions are more appropriate, reliable, and attractive (Chavoshi and Hamidi, 2019). Although it brings a number of advantages such as ease of use, flexibility in learning, and a controllable environment, there are quite a few limitations of e-learning, such as social isolation, lack of face-to-face interaction between teacher and student, connectivity, etc. Although e-learning was not formally adopted as a form of education before this pandemic, now, at the time of the pandemic crisis, most educational institutions are exploring and approaching e-learning to make it easier for students to work at a normal level (Khan et al., 2020).

Although the field of online education is not new and has been studied intensively in recent decades, it has again attracted attention recently, being intensively studied in (Chakraborty et al., 2020; Chavoshi and Hamidi, 2019; Chen et al., 2020; Khan et al., 2020; Kurilovas and Kubilinskiene, 2020; Shahzad et al., 2020; Sitar-Taut and Mican, 2021) due to the fact that pupils and students have been 
forced to participate to the educational process in online format, due to the imposition of social distance restrictions. According to (Chakraborty et al., 2020), there is a lack of studies on how effectively students can interact with teachers and fellow students through various online tools and how effective online assessment techniques are. Only a few researchers have recently covered these issues (Chakraborty et al., 2020; Chen et al., 2020; Khan et al., 2020; Shahzad et al., 2020).

Due to the current context, this paper aims to provide an overview of students' perceptions of the use of mobile technology in online education. The aim of this paper is to contribute to the knowledge in the field, especially to see if online education is considered by students as a suitable solution to their learning needs and requirements. As a result, to achieve the research objectives, we chose to use the well-known Unified Theory of Technology Acceptance and Use (UTAUT) model (Ali and Arshad, 2016; Handoko, 2019; Hoi, 2020; Hussein Mohammad Jawad and Bin Hassan, 2013; Kuciapski, 2016; Nikou and Economides, 2017; Salloum and Shaalan, 2019; Thongsri et al., 2018).

This article is organized as follows: introduction, theoretical aspects, and literature review, research methodology, results, and discussions, respectively, the conclusion. The first part of this paper offers an introduction regarding the field of study, the importance of the current research related to the field of knowledge, and the purpose and objectives. The second part examines the main studies conducted in the field of online education and how the COVID-19 pandemic has influenced major changes around the world. The next section details the research methodology, the results obtained, and discussions on how they influence the daily lives of students. The last section considers conclusions.

\section{THEORETICAL BACKGROUND AND LITERATURE REVIEW}

To study how users interact and accept technology, the Theory of Reasoned Action (TRA) and the Technology Acceptance Model (TAM) were used, but newer research uses models such as the Unified Theory of Acceptance and Use of Technology (UTAUT) (Hussein Mohammad Jawad and Bin Hassan, 2013). UTAUT is one of the most comprehensive models for accepting technology, and the advantage of the UTAUT model is its comprehensiveness, which means that the conceptual and empirical similarities of eight models are included in its design (Chavoshi and Hamidi, 2019). The UTAUT model (Ali and Arshad, 2016; Handoko, 2019; Hoi, 2020; Hussein Mohammad Jawad and Bin Hassan, 2013; Nikou and Economides, 2017; Salloum and Shaalan, 2019) considers that the 
following factors influence the behavioral intention (BI) and use behavior (UB) to accept and use online education, that is: performance expectancy (PE), effort expectancy (EE), social influence (SI) and facilitating conditions (FC). Determining a student's desire to accept and use online education is done with the help of the behavioral intention (BI) and use behavior (UB) constructors (Salloum and Shaalan, 2019). Performance expectancy (perceived usefulness) (PE) is described as the degree to which an individual believes that using the new technology will help achieve benefits in job performance (Ali and Arshad, 2016). Effort expectancy (EE) is defined as the degree of ease with which a new system or technology can be used (Hoi, 2020). Social influence (SI) is considered the degree to which the intention of individuals to use a new system or technology is influenced by others (Hoi, 2020). Facilitating conditions (FC) are described as the extent to which an individual believes that an organizational and technical infrastructure will sustain the use of new technology (Ali and Arshad, 2016).

The paper published by (Kurilovas and Kubilinskiene, 2020) presented the application of a methodology to assess the adequacy, acceptance, and use of information technology tools for students, as well as a case study to evaluate two widely used IT tools when studying the design of human-computer interaction ( HCI) in Lithuanian universities. The evaluation methodology of IT tools presented in the paper is based on well-known principles of multiple criteria decision analysis for identifying quality evaluation criteria and the Educational Technology Acceptance \& Satisfaction Model (ETAS-M) based on the well-known Unified Theory on Acceptance and Use of Technology (UTAUT) model. The authors (Chavoshi and Hamidi, 2019) explored a number of factors, such as technological, pedagogical, social and individual, that affect the acceptance of m-learning in Iran on both a macro- and micro-scale. The results show that the selection of mobile devices as an educational strategy depends on the combination of pedagogical, technological, social and individual factors, and perceived utility is the most effective factor in accepting m-learning in Iran.

The study by (Chen et al., 2020) aimed to analyze the impact of the pandemic on the user experience by obtaining reviews of seven major online education platforms before and after the outbreak of COVID-19. Furthermore, it seeks to learn about changing users' concerns about online education platforms in terms of access speed, reliability, timely information transmission technology, course management, communication and interaction, learning, and technical support. In research published by (Chakraborty et al., 2020), a study was conducted on students' opinions on various aspects of online education during the pandemic. 
The results showed that students felt that they learn better in physical classrooms (65.9\%) considering that online education is stressful and has affected their health and social life. The study conducted by (Shahzad et al., 2020) proposes a theoretical framework and a model to determine the success of e-learning portals. The objective of the study was to verify whether there are differences between women and men in terms of accessibility, quality of services, quality of the system, quality of information, user satisfaction, use of the system, and the success of elearning portals. The results of the study reveal that men and women have a different level in terms of the use of e-learning portals in universities in Malaysia.

The study of (Nikou and Economides, 2017) provides empirical evidence on the acceptance of mobile-based assessment (MBA) and the proposed model, the Mobile-Based Assessment Acceptance Model (MBAAM) describes and predicts around $47 \%$ of the variance of behavioral intention to use mobile-based assessment. The purpose of the study conducted by (Thongsri et al., 2018) employed UTAUT to investigate the factors that influence the intention of learners to use m-learning in developing countries such as Thailand. The results revealed that performance expectancy, cognitive need, affective need and social need had a significant effect on the intention to use m-learning. The study of (Kuciapski, 2016), based on UTAUT, investigated how students from Poland perceive the use of mobile technologies during the study process and used structural equation modelling to analyze data collected from 370 students from two universities.

\section{RESEARCH METHODOLOGY, RESULTS, AND DISCUSSION}

In this empirical study, the applied research methodology is based on the construction of a questionnaire in which the variables were derived following the review of the literature. The questionnaire contains on the one hand demographic profiles and on the other hand questions regarding experience with online learning platforms and the factors that affect the intention to continue using m-learning platforms, namely, the UTAUT model (Ali and Arshad, 2016; Handoko, 2019; Hoi, 2020; Hussein Mohammad Jawad and Bin Hassan, 2013; Kuciapski, 2016; Nikou and Economides, 2017; Salloum and Shaalan, 2019; Thongsri et al., 2018). Five-point Likert scales established in the literature were used to measure the constructors, ranging from 'strongly disagree' (1) to 'strongly agree' (5). Therefore, for perceived utility (PE), questions such as (e.g., "I think m-learning systems are useful for me and allow me to perform tasks faster and more efficiently in the learning process") were used, and for behavioral intention (BI) questions 
such as (e.g., "I intend to continue using m-learning in my learning activity"). Thus, taking into account the specialized literature and the UTAUT model, the following hypotheses were issued:

H1. PE has a positive significant effect on BI of online education.

H2. EE has a positive significant effect on BI of online education.

H3. SI has a positive significant effect on BI of online education.

H4. BI has a positive significant effect on UB of online education.

H5. FC has a positive significant effect on UB of online education.

Samples were collected from university students during the COVID-19 pandemic using a Google survey. A total of 311 subjects participated in this study, all familiar with online education and currently using m-learning platforms. Of the total of respondents, $63.34 \%$ were women and $36.66 \%$ men. Of these, the vast majority, $89.07 \%$ are between 18 and 24 years old. In addition, $42.77 \%$ have up to two years of experience with online educational platforms (e.g., Moodle), and $41.16 \%$ have between 3 and 4 years of experience. In Table 1 we can see in detail the demographic characteristics of the study participants.

Table 1 Sample demographics $(\mathrm{n}=311)$

\begin{tabular}{llrr}
\hline Respondent's demographic & Category & Total & $\%$ \\
\hline Gender & Female & 197 & $63.34 \%$ \\
& Male & 114 & $36.66 \%$ \\
Age & $18-24$ & 277 & $89.07 \%$ \\
& $25-34$ & 34 & $10.93 \%$ \\
Experience with m-Learning products (years) & $<2$ years & 133 & $42.77 \%$ \\
& $3-4$ years & 128 & $41.16 \%$ \\
& 5-6 years & 32 & $10.29 \%$ \\
& $>7$ years & 18 & $5.79 \%$ \\
\hline
\end{tabular}

To analyze the data collected, SmartPLS (Ringle, Christian M., Wende, Sven \& Becker, 2015) was used, which uses PLS-SEM. PLS-SEM and SmartPLS modeling are used successfully in multiple research in the field of education (Nikou and Economides, 2017; Salloum and Shaalan, 2019; Shahzad et al., 2020), e-commerce (Dan-Andrei et al., 2020; Mican, Sitar-Tăut and Moisescu, 2020), or social networks (Mican, Sitar-Tăut and Mihuţ, 2020). The graphical representation of the structural model with the obtained values of path coefficients, $p$ values and $\mathrm{R}^{2}$ can be observed in Fig. 2. The model measurements' assessment in terms of 
their reliability, convergent validity, collinearity issues and model fit was made and all values are in the recommended intervals (Hair et al., 2016).

Table 2 Descriptive statistics

\begin{tabular}{lcccc}
\hline Items & Minimum & Maximum & Mean & Standard Deviation \\
\hline Performance expectancy (PE) & 1 & 5 & 4.287 & 0.756 \\
Effort expectancy (EE) & 1 & 5 & 4.328 & 0.781 \\
Social influence (SI) & 1 & 5 & 3.638 & 1.000 \\
Facilitating conditions (FC) & 1 & 5 & 4.473 & 0.750 \\
Behavioral intention (BI) & 1 & 5 & 4.301 & 0.794 \\
Use behavior (UB) & 1 & 5 & 4.103 & 0.822 \\
\hline
\end{tabular}

The results of the preliminary analysis of the questionnaire can be seen in Table 2 and Figure 2. The results for the mean values and standard deviation are presented in Table 2. The mean value for almost all constructs (PE, EE, FC, and $\mathrm{BI})$ is higher than 4.2 , which leads us to conclude that the respondents strongly agree with these variables, and for SI and UB it is higher than 3.4, which leads us to conclude that they agree with these variables. The standard deviation ranges from 0.750 to 1.000 , which is a very narrow range around the mean.

The percentage of participants' responses for each factor, based on Likert's 5point scale, is shown in Figure 1. Thus, the majority of students $(83.20 \%)$ believe that the use of new technologies, such as m-learning, are useful and will help to obtain benefits in terms of performing faster and more efficiently of work tasks in the learning process. A high percentage of students $(86.28 \%$ ) consider that $\mathrm{m}$ learning systems (e.g., Moodle) are easy to use, that the discovery of various facilities is obvious in such systems, and how to interact with m-learning platforms it is easy and intuitive. Just over half of the students (53.70\%) believe that the intention to use online education and online learning technologies is influenced by others. Most of the students $(89.39 \%)$ consider that in general, the university / faculty and the environment in which they prefer to learn offer them the optimal conditions to be able to benefit from online education. Regarding the intention to accept and continue to use online education in future learning activities, the majority of students $(83.82 \%)$ expressed their agreement to continue using the platforms that facilitate online education. 




Figure 1 Distribution of responses

The structural model identifies the path relationships between the constructs in the research model and the bootstrap method was used to investigate the hypotheses in PLS-SEM. As Figure 2 reveals, performance expectancy (PE) has the most influence on behavioral intention (BI), which has the most influence on use behavior (UB). In addition, regarding the path coefficients of total effects, the final dependent variable use behavior (UB) is mostly influenced by behavioral intention (BI), then by facilitating conditions (FC), performance expectancy (PE), and social influence (SI). Effort expectancy (EE) does not have an effect on behavior intention (BI). As a result, $\mathrm{H} 1, \mathrm{H} 3, \mathrm{H} 4$, and $\mathrm{H} 5$ were supported and $\mathrm{H} 2$ was rejected.

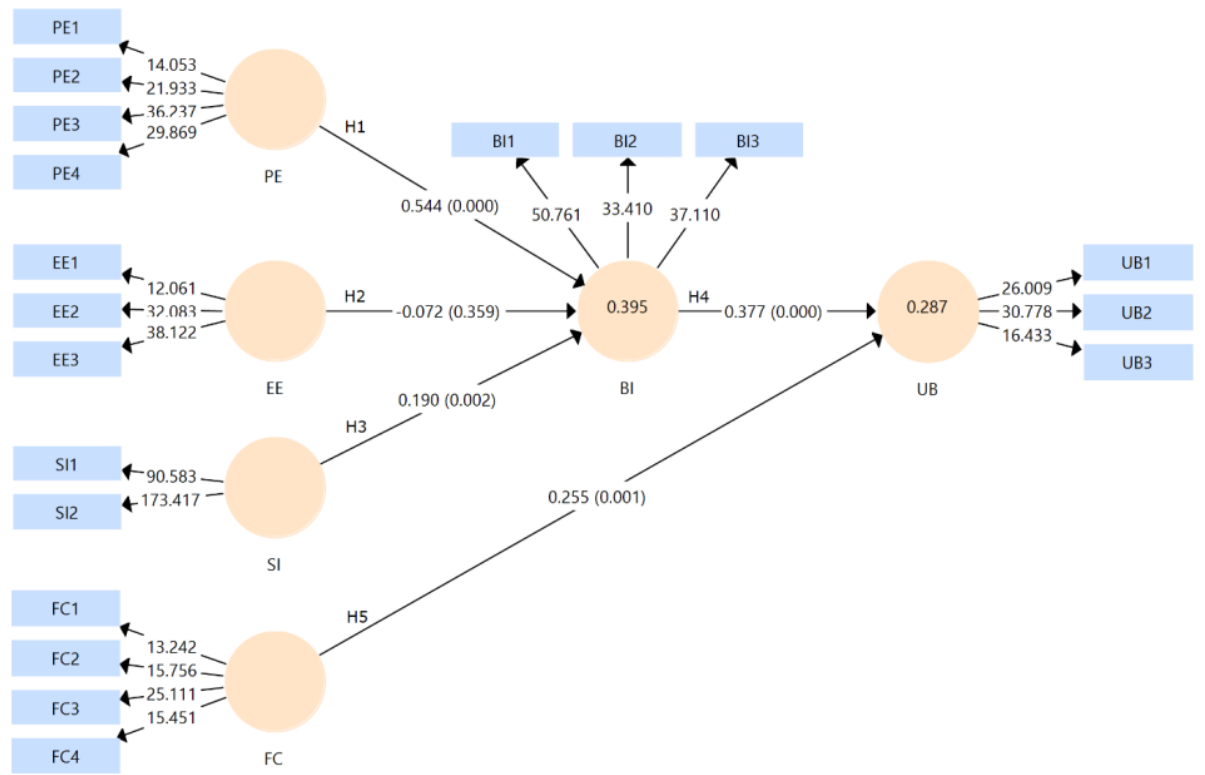

Figure 2 Structural model with the obtained values, of path coefficients, $\mathrm{p}$ values and $\mathrm{R}^{2}$ 
The results of our study have shown that performance expectancy (PE) has a positive significant effect on the behavioral intention (BI) of online education; therefore, the $\mathrm{H} 1$ hypothesis was confirmed. Similar conclusions were drawn by (Hoi, 2020; Hussein Mohammad Jawad and Bin Hassan, 2013; Salloum and Shaalan, 2019; Thongsri et al., 2018) and (Hoi, 2020) also found that performance expectancy is the most powerful predictor of attitude towards the use. The better the performance expectancy (PE) is considered by the students, the higher the behavioral intention (BI), respectively, the use behavior (UB), and the behavioral intention (BI) mediates the relationship between the two variables. Regarding the $\mathrm{H} 2$ hypothesis, the hope of effort (EE) has no effect on the behavioral intention (BI) of online education, as a result, this hypothesis was rejected. These findings confirm those of previous studies, such as those published by (Hoi, 2020; Thongsri et al., 2018), but in contrast to earlier findings of (Hussein Mohammad Jawad and Bin Hassan, 2013; Salloum and Shaalan, 2019).

Social influence (SI) was found to have a positive and significant effect on behavioral intention (BI) of online education, therefore, the $\mathrm{H} 3$ hypothesis is confirmed. These results are in line with those obtained by (Hoi, 2020; Hussein Mohammad Jawad and Bin Hassan, 2013; Salloum and Shaalan, 2019), but the results do not confirm previous research by (Thongsri et al., 2018), which have found no significant effect. The results show that behavior intention (BI) has a positive and significant effect on use behavior (UB) of online education; as a result, the $\mathrm{H} 4$ hypothesis is confirmed. The last hypothesis, H5, is also confirmed, stating that facilitating conditions (FC) has a positive and significant effect on use behavior (UB) of online education. The last two hypotheses are consistent with the research of (Hoi, 2020; Hussein Mohammad Jawad and Bin Hassan, 2013; Salloum and Shaalan, 2019).

\section{Conclusions}

The COVID-19 pandemic has had a major impact on education, and with this sudden shift from offline to online, the question remains whether the adoption of online learning will continue to persist after the pandemic. This study aimed to identify the factors that affect students' acceptance of the use of mobile devices in online education. Using the data collected, about the user experience on online education platforms during the COVID-19 pandemic, both descriptive statistical 
analyzes and modeling using structural equations were performed. Thus, out of the five hypotheses issued, four of them were confirmed, and one was rejected.

The study found that the behavioral intention to adopt online education on mobile devices depends on a multitude of factors related to performance, effort, social influence, etc. Specifically, based on the structural model, it was found that the use behavior of mobile devices in online education is mostly influenced by behavioral intention, which in turn is mostly influenced by performance expectancy. In addition, taking into account the total effects of the path coefficients, use behavior is mostly influenced by behavioral intention, then by facilitating conditions, performance expectancy, and finally by social influence. Instead, our study showed that effort expectancy does not have an effect on behavior intention. In addition, $83.20 \%$ of students believe that online education and the use of new m-learning technologies are useful and contribute to the benefits in terms of more efficient fulfillment of work tasks in the learning process. Moreover, $86.28 \%$ believe that the technologies are simple to use and that interacting with m-learning platforms is simple and intuitive. In terms of their intention to embrace and continue to use online education in future learning activities, $83.82 \%$ wish to use online platforms and education in the future. 


\section{REFERENCES}

1. Ali, R.A. and Arshad, M.R.M. (2016), 'Perspectives of Students' Behavior Towards Mobile Learning (M-learning) in Egypt: an Extension of the UTAUT Model”, Engineering, Technology \& Applied Science Research, Engineering, Technology \& Applied Science Research, Vol. 6 No. 4, pp. 1109-1114.

2. Chakraborty, P., Mittal, P., Gupta, M.S., Yadav, S. and Arora, A. (2020), "Opinion of students on online education during the COVID-19 pandemic", Human Behavior and Emerging Technologies, p. hbe2.240.

3. Chavoshi, A. and Hamidi, H. (2019), "Social, individual, technological and pedagogical factors influencing mobile learning acceptance in higher education: A case from Iran", Telematics and Informatics, Vol. 38, pp. 133-165.

4. Chen, T., Peng, L., Jing, B., Wu, C., Yang, J. and Cong, G. (2020), "The Impact of the COVID-19 Pandemic on User Experience with Online Education Platforms in China", Sustainability, Vol. 12 No. 18, p. 7329.

5. DAN-ANDREI, S.-T., DANIEL, M. and CODRUTA, M. (2020), "Customer Behavior in the Prior Purchase Stage - Information Search Versus Recommender Systems”, Economic Computation and Economic Cybernetics Studies and Research, Vol. 54 No. 3/2020, pp. 59 76.

6. Hair, J.F., Hult, G.T.M., Ringle, C.M. and Sarstedt, M. (2016), A Primer on Partial Least Squares Structural Equation Modeling (PLS-SEM), SAGE Publications.

7. Handoko, B.L. (2019), "Application of UTAUT theory in higher education online learning”, ACM International Conference Proceeding Series, Association for Computing Machinery, New York, New York, USA, pp. 259-264.

8. Hoi, V.N. (2020), "Understanding higher education learners' acceptance and use of mobile devices for language learning: A Rasch-based path modeling approach", Computers and Education, Elsevier Ltd, Vol. 146, p. 103761.

9. Hussein Mohammad Jawad, H. and Bin Hassan, Z. (2013), Applying Utaut to Evaluate the Acceptance of Mobile Learning in Higher Education in Iraq, International Journal of Science and Research, Vol. 4, available at: www.ijsr.net (accessed 12 February 2021).

10. Khan, M.A., Vivek, V., Nabi, M.K., Khojah, M. and Tahir, M. (2020), "Students' Perception towards E-Learning during COVID-19 Pandemic in India: An Empirical Study", Sustainability, Vol. 13 No. 1, p. 57.

11. Kuciapski, M. (2016), "Students acceptance of m-Learning for higher education-UTAUT model validation", Lecture Notes in Business Information Processing, Vol. 264, Springer Verlag, pp. 155-166.

12. Kurilovas, E. and Kubilinskiene, S. (2020), "Lithuanian case study on evaluating suitability, acceptance and use of IT tools by students - An example of applying Technology Enhanced Learning Research methods in Higher Education", Computers in Human Behavior, Vol. 107, p. 106274.

13. Mican, D., Sitar-Tăut, D.-A. and Mihuţ, I.-S. (2020), "User Behavior on Online Social Networks: Relationships among Social Activities and Satisfaction”, Symmetry, Vol. 12 No. 10, p. 1656.

14. Mican, D., Sitar-Tăut, D.-A. and Moisescu, O.-I. (2020), "Perceived usefulness: A silver bullet to assure user data availability for online recommendation systems", Decision Support Systems, North-Holland, p. 113420. 
15. Nikou, S.A. and Economides, A.A. (2017), "Mobile-based assessment: Investigating the factors that influence behavioral intention to use", Computers \& Education, Vol. 109, pp. 56-73.

16. Ringle, Christian M., Wende, Sven, \& Becker, J.-M. (2015), "SmartPLS 3", Boenningstedt: SmartPLS GmbH, available at: http://www.smartpls.com.

17. Salloum, S.A. and Shaalan, K. (2019), "Factors Affecting Students' Acceptance of ELearning System in Higher Education Using UTAUT and Structural Equation Modeling Approaches", Advances in Intelligent Systems and Computing, Vol. 845, Springer Verlag, pp. 469-480.

18. Shahzad, A., Hassan, R., Aremu, A.Y., Hussain, A. and Lodhi, R.N. (2020), "Effects of COVID-19 in E-learning on higher education institution students: the group comparison between male and female", Quality \& Quantity, available at:https://doi.org/10.1007/s11135020-01028-z.

19. Sitar-Taut, D.-A. and Mican, D. (2021), "Mobile learning acceptance and use in higher education during social distancing circumstances: an expansion and customization of UTAUT2", Online Information Review, Vol. 45 No. 5, pp. 1000-1019.

20. Thongsri, N., Shen, L., Bao, Y. and Alharbi, I.M. (2018), "Integrating UTAUT and UGT to explain behavioural intention to use M-learning: A developing country's perspective", Journal of Systems and Information Technology, Emerald Group Publishing Ltd., Vol. 20 No. 3, pp. 278-297. 